\title{
Inquietações e colaborações dos docentes no uso das TDIC durante o COVID-19
}

\author{
Nathalino P. Britto ${ }^{1}$, Elizabeth S. Furtado ${ }^{2}$, Liádina C. Lima ${ }^{3}$ \\ ${ }^{123}$ Programa de Pós-Graduação Stricto Sensu em Informática Aplicada - Universidade \\ de Fortaleza (UNIFOR) \\ 60.811-905 - Fortaleza - CE - Brazil \\ \{nathalinopacheco\}@gmail.com, elizabet@unifor.br, liadina@unifor.br
}

\begin{abstract}
In virtue of the social isolation steemed from the Coronavirus (COVID-19), whereby only basic services were kept active, the standard education had to stop for crafting a somewhat new way to go on its schedule. Thus, we wonder which digital information and communication technologies were employed by teachers as well as the reason as for their personal choices, given the needs and anxieties regarding doubts about teaching. We gathered 528 messages through WhatsApp gadget between March and June 2020 and obtained 15 tools used, 6 purposes for use and 5 messages with questions and/ or opinions as result.
\end{abstract}

Resumo. O isolamento social provocado pelo Coronavírus (COVID-19), mantendo-se em funcionamento apenas os serviços essenciais, a educação presencial parou criando um novo normal para a continuação do calendário letivo na modalidade online. Investigamos quais as tecnologias digitais de informação e comunicação estiveram presentes nos questionamentos $e$ opiniões entre os docentes e o motivo das suas escolhas pessoais, além das necessidades e as ansiedades para a continuação do ensino. Captamos 528 mensagens no aplicativo WhatsApp no periodo entre março e junho de 2020 e obtemos como resultado 15 ferramentas utilizadas, 6 propósitos na utilização e 5 mensagens com questionamentos e/ou opiniões.

\section{Introdução}

Em março de 2020, no Brasil, iniciou-se um processo de confinamento devido à pandemia do novo Coronavírus (COVID-19) de modo consequente, prelúdio de uma caminhada para o ensino na modalidade online que ausentou os agentes da educação presencial. Compartilhamos e compreendemos a modalidade online pela ótica de Santos (2009), que aponta para um conjunto de ações de ensino-aprendizagem ou atos de currículo mediados por interfaces digitais que potencializam práticas comunicacionais interativas e hipertextuais. Santos (2009) entende as tecnologias digitais como meios e, enquanto tais, não devem ser utilizados unicamente como as teleconferências, videoconferências, Ambientes Virtuais de Aprendizagem (AVAs) etc. Conforme Pimentel e De Carvalho (2020), a utilização dos AVAs por docentes na modalidade Educação à Distância (EAD) difunde um exclusivismo, o que cria uma certa aversão a outros sistemas computacionais, conjecturando que tudo deveria ser desempenhado exclusivamente dentro dos AVAs. 
Diante das circunstâncias e incertezas da continuidade do ano acadêmico presencial, diversas instituições postularam aos seus docentes e coordenadores pedagógicos mudanças disruptivas à prossecução do ensino. Nesta ocasião, os docentes descobrem adversidades comuns as novas experiências como deixar de utilizar o quadro branco de forma trivial sem as devidas ferramentas computacionais para facilitar a escrita; devem engajar os discentes à distância e avaliarem a pontualidade; aplicação de exercícios e/ou provas manuseando sistema computacional apropriado e ainda terem o zelo em preservar aulas dinâmicas, por exemplo. Na tentativa de contornar estes problemas e a dependência exclusiva pela instituição, assiste-se em apresentações virtuais (Webinar PGCTIn, 2020; Quarta Docente, 2020; Wong-Villacres e colaboradores, 2020) e publicações como na revista online Horizontes (Rodrigues, 2020) uma confluência e mobilização dos próprios professores para o uso de diversos aplicativos de mensagens instantâneas e multiplataformas, como o Telegram, WhatsApp, Google Hangouts e entre outros como meio para atingirem seus objetivos.

Estes acontecimentos motivaram a presente pesquisa, razão pela qual buscamos saber como se passam as interações entre os docentes diante do desafio de ter que realizar as rupturas mencionadas. Com efeito, trata-se aqui de um estudo de caso através do qual se analisa a comunicação virtual colaborativa entre os docentes de um certo curso de uma instituição de ensino superior privada. Os dados captados remontam ao período de março até junho de 2020. Ao se comunicarem, os docentes faziam colocações, expressavam suas opiniões pessoais sobre as mudanças e desafios perante as principais tecnologias digitais de informação e comunicação (TDIC) disponíveis no mercado, que poderiam ser usadas ou não. Diante da problemática apresentada acima, a Questão (Q): Quais as necessidades e desafios dos docentes para continuarem o processo de ensino na modalidade online e ainda manterem os discentes engajados em aula, enquanto existe um diálogo extenso de várias TDIC como possível solução?.

\section{Trabalhos Relacionados}

Rodrigues (2020) descreveu uma experiência nas universidades federais do Brasil, ocorrida em abril de 2020, cujas aulas foram remotas via ambientes tecnológicos AVA Moodle e o Google Classroom, de acordo com o interesse dos professores. Os desafios destacados foram: o acompanhamento das atividades remotas dos discentes, normatização das ações e dos procedimentos e a formação dos professores. $\mathrm{O}$ suporte aos docentes decorreu por meio de tutores e em eventos online (semana de formação e Webinar) com o intuito de capacitar e tornar possível o diálogo entre os docentes na instituição. A adesão às disciplinas remotas do evento online, na semana de formação, fora disponibilizada em diversos canais, contando com a participação de 81 professores, no total de 509 docentes da instituição. No canal da plataforma Moodle, havia o fórum concedendo o diálogo entre os docentes e fomentando a colaboração com a narrativa de experiências. O evento encerrou com encontro síncrono em alguma plataforma virtual para o compartilhamento de impressões sobre os assuntos decorridos durante o evento, participando 69 professores. As principais dificuldades enfrentadas pelos docentes no trabalho com as disciplinas remotas conduzem a "rever as próprias práticas pedagógicas, reposicionar-se no papel de professor mediador e não de detentor único do conhecimento e repensar as práticas avaliativas" (Rodrigues, 2020).

Os autores Ludovico et al (2020) expõem a metodologia pedagógica no cenário pandêmico da COVID-19 com um total de 9 docentes do ensino básico e superior das 
redes pública e privada nos estados do Paraná e Rio Grande do Sul. A narrativa contou com uma metodologia qualitativa, segmentada por categorias (estratégias de enfrentamento e ferramentas, suporte aos docentes e aos pais). A entrevista dos docentes aconteceu por meio do aplicativo WhatsApp, com o propósito também da identificação dos recursos utilizados para viabilizar o ensino remoto emergencial destacando-se as ferramentas: e-mail, Moodle, Google Classroom, Google Meet, WhatsApp, Microsoft Teams, Software Powerpoint, arquivos com extensões pdf, dentre outros. Evidenciou-se como finalidade do uso a simulação de um quadro branco para escrever, comunicação com os discentes, meio para receber trabalhos e lecionar de forma síncrona, por exemplo. As dificuldades referidas são a falta de recursos na utilização desses sistemas, limitações de formação para o uso da TIC (Tecnologias da Informação e Comunicação) e a efetivação de práticas de ensino e aprendizagem em contextos não presenciais adaptadas às suas especificidades (disciplina, recursos, idade dos estudantes, fase de escolarização etc.).

Verificaram Sturion et al (2011) a satisfação dos discentes, dificuldades dos docentes e a eficácia na utilização de novas tecnologias. Vinte e cinco docentes participaram do questionário, obtendo como característica uma amostra intencional reunindo professores que ministravam disciplinas com $50 \%$ do conteúdo via web. Sobre as TIC utilizadas, tiveram unanimidade na utilização do Datashow, 18 docentes utilizavam algum software específico na sua área e 14 professores utilizavam alguma multimídia. Suas dificuldades estão ligadas à insegurança no uso dessas tecnologias. Infelizmente, os autores não deram ênfase às tecnologias utilizadas na modalidade à distância e aos seus propósitos de uso.

Nesta pesquisa, o foco está na colaboração entre os professores que relatam suas inquietações se ajudam e outros comportamentos inerente a situação vivenciada.

\section{Metodologia}

A técnica empregada foi de observação assistemática ou, conforme Marconi (2003), rotulada também como natural, informal, comum, simples, ocasional e/ou acidental, com o propósito de levantar e repertoriar os fatos da realidade, sem que o pesquisador utilize meios técnicos especiais ou precise fazer perguntas diretas, por meio de questionários estruturados e/ou semiestruturados.

Durante o período letivo iniciado em 23 de março, até o final de junho de 2020, iniciamos um processo de coleta de dados no aplicativo multiplataforma de mensagens instantâneas e chamadas de voz para smartphone o WhatsApp. As coletas ocorreram em um grupo constituído por professores que antes da pandemia lecionavam exclusivamente na modalidade de ensino presencial e aplicavam abordagens pedagógicas baseadas em projetos. Portanto, de acordo com Marconi (2003), a melhor ocasião para o registro dos fatos é o local onde eles ocorrem, e isto reduz as tendências seletivas e a deturpação na reevocação. O grupo em questão foi criado pela coordenadora do curso de tecnologia com o objetivo de apoiar os docentes envolvidos. Não capturamos dados sensíveis e caso houvesse mensagens textuais com citação(ões) do(s) nome(s) do(s) docente(s), disciplina(s) e/ou discente(s), prontamente seriam suprimidas, preservando o anonimato. Os membros participantes do grupo previamente foram informados desta pesquisa e a captação de dados seguiram o rígido controle de 
supressão, conforme já informado anteriormente; até por não existir interesse na autoria, mas sobre a finalidade do recurso mencionado para a comunidade.

\subsection{Participantes e Dados Coletados}

As principais características dos 35 participantes desse grupo de WhatsApp foram: diferentes níveis de experiência no exercício do magistério e na utilização de tecnologias; idade entre 33 a 60 anos; a maioria do gênero masculino (70\%); todos com a titulação de mestrado. Conclusão das particularidades, temos um grupo heterogêneo nos requisitos experiência no exercício do magistério e emprego de tecnologias; e homogêneo pelo propósito de lecionar utilizando a mesma abordagem pedagógica que tem como essência "experiências práticas", instigando o discente na participação e construção do aprendizado. Captamos 528 postagens (mensagens) nos diálogos entre os professores, considerando os três temas: 1) Sistemas computacionais mencionados; 2) Postagens feita pelo docente para descrever sugestões e/ou suas dúvidas no emprego desses sistemas computacionais; e 3) Necessidades e desafios pessoais frente às mudanças do professor.

Das postagens coletadas, algumas foram excluídas por se tratar de mensagens com recorrências nas citações de outros professores a respeito de um determinado ambiente computacional e do contexto em questão. A comunicação no aplicativo WhatsApp poderá ocorrer de forma assíncrona. Nesse aspecto, existe o ressurgimento de uma mesma dúvida e, consequentemente, a replicação das respostas anteriores (repetição). À medida que o diálogo foi acontecendo, houve a captura espontânea, sem a devida preparação, mas classificada de acordo com os temas mencionados. Marconi (2003) revela que a observação de fatos e fenômenos deve ser feita tal como eles ocorrem espontaneamente, tanto na coleta de dados a eles referentes, como no registro de variáveis que se presumem relevantes para analisá-los.

\section{Resultados e Discussão}

As quinze (15) ferramentas foram citadas com diversas finalidades e/ou funcionalidades e sendo de empresas concorrentes. A classificação dessas ferramentas levou em consideração os temas 1 e 2, obtendo como resultado a figura 1 por ordem alfabética e com os respectivos quantitativos crescente de suas menções nos diálogos do grupo de WhatsApp.

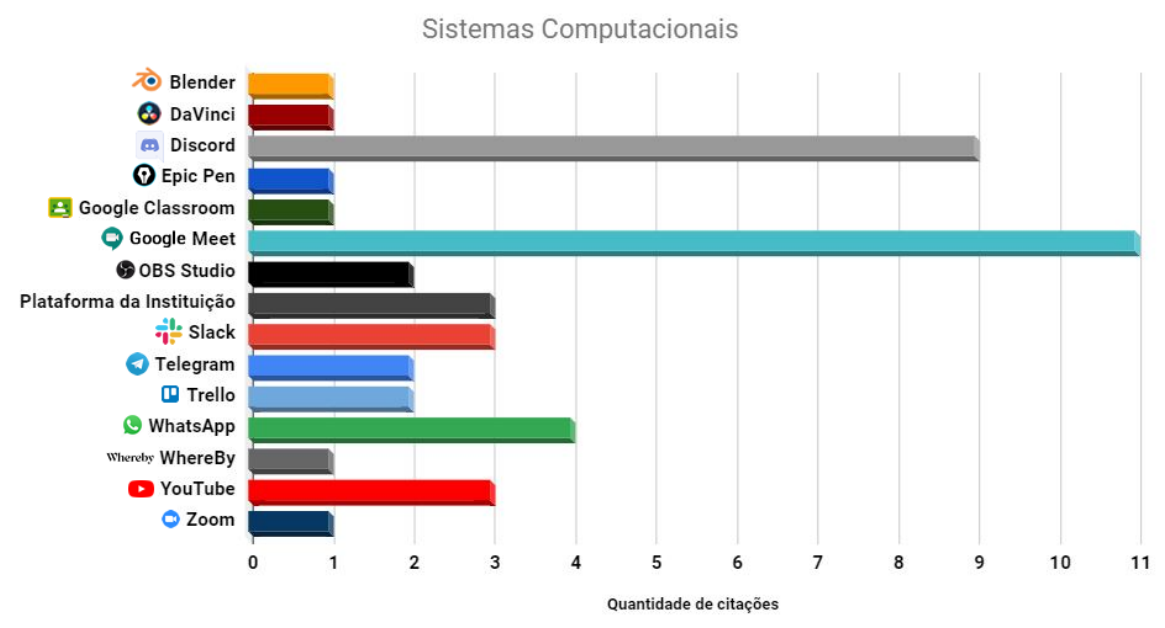




\section{Figure 1. Sistemas computacionais sugeridos e/ou empregados}

Dentre as mais citadas, estão o Google Meet (11 citações), Discord (9 citações) e o WhatsApp (4 citações). O Google Meet foi a plataforma de comunicação mais enfatizada nos diálogos pelo fato de ser disponibilizado gratuitamente aos seus usuários e pela facilidade na geração de link com intuito de lecionar. A ferramenta multiplataforma Discord, inicialmente projetada para a comunidade de jogos, teve um papel relevante na execução de muitas atividades, fato narrado pelos docentes e inclusive recomendada por alguns discentes por contribuir para a organização de salas de voz e, consequentemente a realização de atividades em grupos, possibilitando ainda apresentações coletiva e individual. A plataforma de comunicação o slack, teve 3 citações, mas é semelhante a algumas funcionalidades do Discord. O WhatsApp (4 citações) e o Telegram (2 citações) foram utilizados para a criação de grupos por disciplinas na área de tecnologia e em diversas disciplinas afins aos cursos, com o intuito e aspectos de criar um canal de comunicação para organizar o cronograma de atividades durante o período letivo e sanar eventuais dúvidas com relação às atividades desenvolvidas pelos alunos, além do compartilhamento de links com as aulas gravadas e disponibilizadas no YouTube (assíncrono) e ao lecionar (síncrona) seja pelo Google Meet, Slack, Discord etc. A gravação das aulas teve como protagonista o software para streaming e gravação, o OBS Studio (2 citações), caso a ferramenta utilizada não houvesse a disponibilidade do recurso "gravar". É concebível que alguns aplicativos como o Blender, DaVinci Resolve, Epic Pen e WhereBy, sejam citados apenas uma vez, pois os dois primeiros softwares têm a complexidade inerente à interface, por ambas serem ferramentas robustas e com diversas finalidades, além da edição de vídeos (Furtado, 2013; Garrett, 2016).

A ferramenta Epic Pen foi mencionada para desenhar, escrever e evidenciar os textos apresentados, manipulando diretamente os elementos no aplicativo. Já o website WhereBy e o aplicativo Zoom são similares ao Google Meet, mas o WhereBy tem uma peculiaridade de não exigir software ou aplicativo para a utilização. A única citação feita ao Zoom mencionou o noticiário e fez ressalvas sobre a utilização. De fato, houve notícias em diversos portais de tecnologias no Brasil no mês de abril de 2020 sobre o vazamento de dados e a exposição dos usuários na plataforma. Outro ambiente que recebeu apenas uma menção foi o Google Classroom, recomendado como um meio de gerenciar os exercícios disponibilizados aos discentes e a criação de aulas interativas. Para concluir, o Trello ( 2 citações) é um gerenciador de projeto web que teve como finalidade o gerenciamento e acompanhamento das equipes na execução das suas atividades em grupo.

\subsection{Necessidades e Desafios do Docente}

Durante a identificação das ferramentas mencionadas pelos docentes das postagens, analisamos também seus desafios, comportamentos e emoções. Identificamos desafios e necessidades dos docentes (Q) que se referiram principalmente a terem que manter $o$ processo de ensino em uma modalidade totalmente diferente da convencional (a presencial), bem como manter o discente engajado, peça-chave na metodologia pedagógica na instituição de pesquisa. As necessidades dos docentes mais correntes foram as seguintes:

1. canais de comunicação por vídeo, áudio e texto ao lecionar; 
2. canal de comunicação apenas por texto assíncrono para avisos e dúvidas pontuais sobre atividades em vigor;

3. salas públicas e privadas para diálogo entre os discentes e docente e, inclusive, entre membros do mesmo grupo;

4. gravação e edição de vídeos para disponibilização futura; compartilhamento das videoaulas; e

5. meios para a escrita de conteúdos práticos em tela ao lecionar.

As postagens dos professores sobre essas necessidades e preferências revelam associações com as funcionalidades dos sistemas citados na Figura 1, e com os seus desafios frente às intenções de uso por esses sistemas. Considere os seguintes exemplos de postagens: "Como aplicar exercícios e avaliar o discente pontualmente e diretamente, enquanto os próprios alunos estão em diálogos no canal de comunicação?" e "Por que não devo utilizar esse aplicativo para aplicação de exercícios?", essas indagações estão associadas às necessidades: $1,2 \mathrm{e} 3$, cujas possibilidades são relativas às funcionalidades do Discord e outros; "Como compartilhar o acesso a atividades, aulas gravadas e comunicados, apenas por link sem a solicitação do número de telefone do aluno?", correlacionado à necessidade 2 e congruente à funcionalidade de criação de grupos disponível nos aplicativos WhatsApp ou Telegram, sendo este último citado com maior apelo para o uso devido a privacidade; e "Como disponibilizar as minhas aulas online depois da gravação de forma eficiente? Faço a edição em qual software?”, foram aludidos a sistemas externos, por exemplo, o Youtube com acesso privado às videoaulas por meio de link e a edição de vídeo utilizando os softwares Blender e DaVinci Resolve. Inclusive foi enfatizado que apenas o DaVinci Resolve atenderia a necessidade, relacionado a necessidade 4 .

Identificamos também postagens que continham dúvidas dos docentes que não estavam associadas diretamente às funcionalidades dos sistemas citados na Figura 1. Pudemos perceber que as soluções tecnológicas existentes são insuficientes e/ou inapropriadas. Citamos, a seguir, exemplos de postagens revelando as necessidades dos professores e o apoio na busca de soluções alternativas foi notório. São eles:

- "Utilizava o quadro branco para escrever cálculos, teorias, realizar exercícios e etc, em vista disso, qual aplicativo online preencheria essa necessidade?". Para indagações deste tipo foram identificadas as seguintes sugestões dos docentes, como a compra de uma mesa digital, por exemplo. A instalação do Epic Pen foi sugerida, mas com ressalvas da necessidade de experiência ao manusear o mouse com a finalidade de escrita;

- “Ao lecionar utilizando serviços de comunicação por vídeo, notei que os discentes não participam. Como transformar a aula em aula dinâmica com outras ferramentas?"; esse desconforto identificado em vários diálogos foi correlacionado ao tempo da aula, à frequência e outros fatores narrados abaixo. Os docentes relataram o cansaço em aulas expositivas contínuas com a mesma duração hora/aula na modalidade presencial, resultando em reclamações dos discentes e desmotivação na duração da aula, muitas vezes, sendo sugerido pelo discente a pausa para atividades complementares e/ou diálogo entre os mesmos. Além de dificuldades com o engajamento do aluno e com sua interação na sala virtual, a timidez e insegurança dos alunos foram citadas como fatores 
impeditivos para a exposição de ideias. Esse fator foi mais citado no primeiro mês de aula remota. Conforme registros em março, o aluno dificilmente se colocava na aula de forma atuante, não ligava a câmera e não falava. A sensação registrada pelos professores era de receio dos alunos, visto que as aulas estavam sendo gravadas e a exposição da imagem e da voz geram insegurança aos alunos;

- "Ainda que existisse uma ferramenta perfeita, teríamos o impacto da inexperiência e consequentemente tempo para o aprendizado", disse um certo docente. Neste contexto, não poderíamos deixar de mencionar que os atuais AVAs existentes e usados na modalidade educação à distância passam por uma reavaliação e inclusive alterações na tentativa de atender ao anseio dos coordenadores pedagógicos, professores e alunos, conforme é notório na descrição da evolução dos AVAs descrito pelos autores Gomes e Pimentel (2020) "surgiram modelos de AVAs baseados na metáfora de redes sociais" (Gomes e Pimentel, 2020);

- "Não consigo saber como as equipes de alunos colaboram na resolução de problemas complexos, sequer auxilia-lo em tempo real”. Em abril, um professor gravou um vídeo e o disponibilizou no grupo demonstrando como ele usava o Discord para este fim. Surgiram muitas dúvidas dos outros docentes. Diante dos interesses dos colegas, o professor se voluntariou a realizar uma oficina virtual, participaram 33 professores e inclusive a coordenação do curso de tecnologia.

\section{Conclusão}

Este artigo apresentou dados deste período histórico da humanidade, especificamente da educação em que houve a passagem inesperada e obrigatória da educação presencial para a educação online por um grupo de docentes. As soluções próprias dos docentes observadas diante dos depoimentos compartilhados sobre seus desafios e com o apoio da instituição, foram os alicerces à criação de oportunidades para o semestre não parar. Este trabalho narrou as percepções dos docentes sobre suas necessidades e desafios frente às utilidades das ferramentas mencionadas e suas dificuldades para usá-las. Percepções estas obtidas somente das suas narrativas. Considerando o período de muito trabalho dos professores, mas a aplicação de um questionário, neste início do novo semestre, faz-se necessária para enriquecer essa percepção em análise.

A instituição que passou por esse dilema de mudanças, hoje encontra-se em um processo de implementação de um dos AVAs mais conhecidos e utilizados no mundo: o Moodle. Durante o processo de coleta de mensagens no grupo de WhatsApp mencionado, rapidamente descobrimos que existe uma rejeição por alguns docentes na implementação do novo ambiente e retornando para a seção de resultados podemos supor que esta reação é decorrente do fato segundo o qual os docentes vivem muitas inquietações e/ou a outra possibilidade pode ser o descontentamento na adoção incondicional por este AVA. Houve um semestre em que os docentes se viraram e tiveram liberdade para adotar o que desejaram; agora eles têm que abandonar suas escolhas. Para um estudo avançado, pretendemos fazer uma análise longitudinal sobre o período de combinação entre os ensinos presencial e online (ensino híbrido) devido ao abrandamento das restrições de isolamento social. Isto permitirá definir requisitos para o ensino híbrido. Enquanto as aulas presenciais não retornam, iremos também aplicar 
questionários aos docentes e discentes, com o intuito de avaliar outras variáveis como as causas das dificuldades na utilização ou não das ferramentas e a satisfação ao adotarem os meios escolhidos e a relação entre o ideal e o real em diferentes cenários educativos.

\section{Referencias}

Furtado, T. B. (2013). TechTudo. Disponível em: https://www.techtudo.com.br/tudosobre/blender.html. Acesso em: 12 set. 2020.

Garrett, F. (2016). Davinci resolve 12. TechTudo. Disponível em: https://www.techtudo.com.br/tudo-sobre/davinci-resolve-12.html. Acesso em: 12 set. 2020.

Gomes, A. S.; Pimentel, E. P. (2020). Ambientes Virtuais de Aprendizagem para uma Educação mediada por tecnologias digitais. Informática na Educação. CEIE-SBC. Disponível em: https://ieducacao.ceie-br.org/ava/. Acesso em: 27 jun. 2020.

Ludovico, F. M. et al. (2020). COVID-19: desafios dos docentes na linha de frente da educação. Interfaces Científicas-Educação, v. 10, n. 1, p. 58-74. Disponível em: https://periodicos.set.edu.br/educacao/article/view/9166. Acesso em: 22 out. 2020.

Marconi, M. A.; Lakatos, E. M. Fundamentos de metodologia científica. 5.ed. São Paulo: Atlas, 2003.

Pimentel, M.; De Carvalho, F. S. P. (2020). Princípios da Educação Online: para sua aula não ficar massiva nem maçante. Revista Horizontes. Disponível em: http://horizontes.sbc.org.br/index.php/2020/05/principios-educacao-online/. Acesso em: 25 jun. 2020.

Quarta docente - EF Anos Iniciais. (2020). Experiências educativas no trabalho remoto durante a pandemia. 1 vídeo $(57 \mathrm{~min} 58 \mathrm{seg})$. Disponível em: https://youtu.be/X1toZBxw_0U. Acesso em: 14 out. 2020.

Rodrigues, A. (2020). Ensino remoto na Educação Superior desafios e conquistas em tempos de pandemia. Disponível em: http://horizontes.sbc.org.br/index.php/2020/06/ensino-remoto-na-educacao-superior/. Acesso em: 22 out. 2020.

Santos, E. (2009). Educação online para além da ead: um fenômeno da cibercultura. Actas do $\mathrm{X}$ Congresso Internacional Galego-Português de Psicopedagogia. Disponível

em: https://www.educacion.udc.es/grupos/gipdae/documentos/congreso/xcongreso/pdfs/t 12/t12c427.pdf. Acesso em: 09 set. 2020.

Sturion, L. et al. (2011). Uma Experiência da Utilização das TICs no Ensino Superior Através de um Sistema Semipresencial. Revista de Ensino, Educação e Ciências Humanas, v. 12, n. 1.

Webinar PGCTIn. (2020). Ensino híbrido em tempo de pandemia: como iniciar com alunos e professores. 1 vídeo $(02 \mathrm{~h} 41 \mathrm{~min} 15 \mathrm{seg})$. Disponível em: https://youtu.be/CSqGHGViSZo. Acesso em: 22 mai. 2020.

Wong-Villacres, M. et al. (2020). "Decolonizing Learning Spaces for Sociotechnical Research and Design". Conference Companion Publication of the 2020 on Computer Supported Cooperative Work and Social Computing. 2020. 